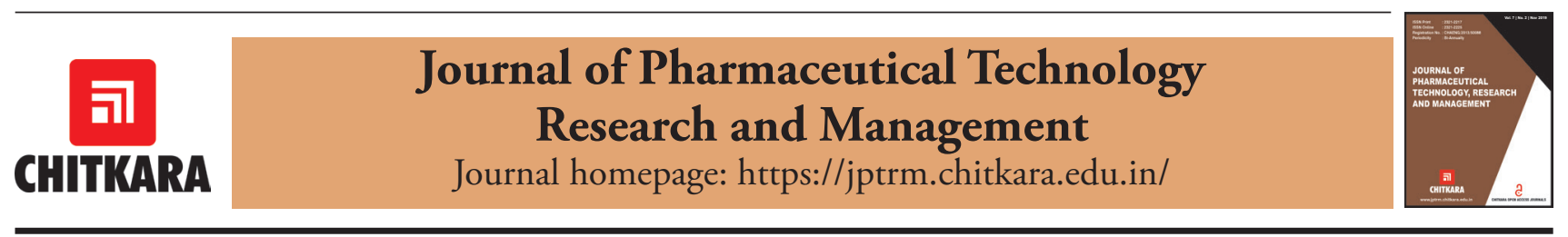

\title{
Improving Physicochemical Properties of Repaglinide Through Pharmaceutical Adduct Formation
}

\author{
Sharen Gill ${ }^{(1 D}$ and Poonam Arora ${ }^{2 *}(\mathbb{D})$ \\ ${ }^{1}$ GHG Khalsa College of Pharmacy, Gurusar Sadhar, Ludhiana, Punjab-141104, India \\ ${ }^{2}$ Chitkara College of Pharmacy, Chitkara University, Punjab-140401, India \\ 'shreengill@gmail.com \\ 2*poonam.arora@chitkara.edu.in (Corresponding Author)
}

\section{ARTICLE INFORMATION}

Received: February 11, 2020

Revised: March 26, 2020

Accepted: April 21, 2020

Published Online: May 20, 2020

Keywords:

Solubility, Repaglinide, Molecular adducts,

Soluplus, HPMC

\begin{abstract}
Background: Many formulation strategies are presently in development in pharmaceutical industry. However, the formation of pharmaceutical adducts is considered to be the most appropriate technique for improving the drug solubility and dissolution as no chemical bond changes are involved in this technique.

Purpose: This technique is highly used for compounds which are not able to give viable formulation products with standard techniques such as salt formation and polymorph generation. In the present study, this method is applied to repaglinide, which is an hypoglycemic agent, with compromised solubility. Methods: The adducts were prepared by slow evaporation method and characterized using DSC, FTIR and PXRD studies. The solubility and dissolution studies were carried out to determine the increased solubility of drug in adducts. The drug amount interacted with coformers has also been determined.

Results: The present study demonstrates the improvement in solubility and thus dissolution of repaglinide in adducts.

Conclusion: The adducts formed in the present study can be further exploited to prepare formulation of repaglinide adducts with better physicochemical characteristics.
\end{abstract}

improve the solubility and dissolution rate of repaglinide

\section{Intoduction}

Many pharmaceutical ingredients are not able to reach the market because of their poor solubility profile which inturn provides limited dissolution and gastrointestinal absorption (Shan \& Zaworotko, 2008; Bhogala et al. 2005). The combination of pharmaceutical ingredient with coformers to form pharmaceutical adducts provides an opportunity to improve these physicochemical parameters (Yadav et al., 2009). These adducts are held together by hydrophobic interactions which do not alter the chemical properties of the active ingredient (Upadhyay et al., 2011; Friščić \& Jones, 2010). These characteristics make pharmaceutical adducts a popular alternative to the traditional dissolution improving methods (Mirza et al., 2008; Babu \& Nangia, 2011). Therefore, identification and characterization of pharmaceutical adducts plays a significant role in the field of pharmaceutical drug formulation development (Desiraju, 2010).

Repaglinide (Rep), which is an oral hypoglycemic agent, belongs to BCS class 2 and the solubility of this molecule in water is found to be $0.0340 \mathrm{mg} / \mathrm{ml}$ indicating that it is practically insoluble in aqueous medium. Repaglinide has two pKa values at 4.19 and 5.78, which makes it a weakly acidic compound, however the drug molecule is ionized at higher $\mathrm{pH}$ values. The present study has been designed to and hence its oral absorption across the gastrointestinal tract by preparing multicomponent adducts.<smiles>CCOc1cc(CC(=O)NC(CC(C)C)c2ccccc2N2CCCCC2)ccc1C(=O)O</smiles>

Figure 1: Chemical structure of Repaglinide.

\section{Experimental}

\subsection{Materials}

Repaglinide was obtained as a gift sample from Aurbindo Pharma, Hyderabad India. HPMC, soluplus, sodium acetate, gallic acid, thiourea, benzoic acid, ascorbic acid and caffeine were procured from Himedia Laboratories, Mumbai, India. The methanol used in the study is of analytical grade.

\section{Preparation of Cocrystal}

The co-crystals are prepared by slow evaporation method containing drug to polymer ratio of $1: 2 \mathrm{w} / \mathrm{w}$ respectively for all adducts i.e. B1, B2, B3, B4, B5, B6, B7, B8 (Table 1). 
1. Accurately weighed repaglinide in molar ratio and dissolved in $10 \mathrm{ml}$ methanol.

2. In a separate beaker co-former for different batches in molar ratio was taken and dissolved in $10 \mathrm{ml}$ methanol.

3. Both the solutions were mixed properly and kept overnight for slow evaporation of solvent under fume chamber at room temperature.

4. The procedure was repeated with each co-former in triplicate.

5. The multicomponent adducts were collected and characterized to determine the optimum co-former for repaglinide adducts.

Table 1: Composition of different adducts.

\begin{tabular}{|l|l|l|l|}
\hline Coding & Drug & Co-former & $\begin{array}{l}\text { REP: Co- } \\
\text { former (w/w) }\end{array}$ \\
\hline B1 & Rep & Soluplus & $1: 2$ \\
\hline B2 & Rep & HPMC & $1: 2$ \\
\hline B3 & Rep & Sodium acetate & $1: 2$ \\
\hline B4 & Rep & Gallic acid & $1: 2$ \\
\hline B5 & Rep & Thiourea & $1: 2$ \\
\hline B6 & Rep & Benzoic acid & $1: 2$ \\
\hline B7 & Rep & Ascorbic acid & $1: 2$ \\
\hline B8 & Rep & Caffeine & $1: 2$ \\
\hline
\end{tabular}

\subsection{Characterization of Adducts}

\subsubsection{Percentage Yield}

1. The obtained adducts were weighed accurately on analytical weighing balance and recorded.

2. The initial weight of components was calculated by adding the weight of repaglinide and co-former.

3. The percentage yield was calculated with the help of formula:

$\%$ yield $=$ weight of adducts/initial weight of components $\times 100$.

\subsubsection{Melting Point}

1. Small amounts of drug, co-former and its adduct were filled in separate capillary tubes with one end sealed for determining the melting points.

2. The capillaries were inserted in melting point apparatus and the apparatus was turned on.

3. The temperature at which the drug, co-former and co-crystal melt was noted with the help of laboratory thermometer.

4. The procedure was repeated with all co-formers taken with their respective co-crystals and there melting point was noted.

\subsubsection{Drug-Coformer Interaction}

1. Accurately weighed $10 \mathrm{mg}$ of adduct and dissolved in methanol to get a clear solution.

2. From this, $0.1 \mathrm{ml}$ of solution was taken and transferred to a volumetric flask of $10 \mathrm{ml}$ capacity and the volume was made upto mark with methanol.

3. From the above solution, again $1 \mathrm{ml}$ of solution was taken and transferred to $5 \mathrm{ml}$ volumetric flask and the final volume was made upto the mark.

4. The amount of drug entrapped was estimated with the help of UV spectrometer at $240 \mathrm{~nm} \lambda_{\max }$.

\subsubsection{Fourier Transform Infra-Red Spectroscopy}

Fourier transform infra-red spectroscopy (FTIR) spectrum is characteristic property of a drug for its identification. It is used to identify the functional groups in the molecule. The drug was scanned at $4 \mathrm{~mm} / \mathrm{s}$ at $2 \mathrm{~cm}^{-1}$ resolution over a wave number region of 400 to $4000 \mathrm{~cm}^{-1}$. The characteristic peaks at particular wave number were recorded and checked for characteristic functional groups present in molecular structure of the drug molecule.

\subsubsection{Optical Microscopy}

The microscopic study was done with the help of optical microscopy by Olympus. The sample was placed on glass slide and observed under microscope at 10x and the images were recorded.

\subsubsection{Aqueous Solubility}

1. Accurately weighed $10 \mathrm{mg}$ of adduct and transferred to vials containing $1 \mathrm{ml}$ distilled water.

2. The vials were kept in water bath shaker at room temperature for 24 hours.

3. Then, the vials were removed and the solution was centrifuged to settle down the undissolved material.

4. The supernatant was estimated for drug content with UV spectrometer at $240 \mathrm{~nm} \lambda_{\max }$.

\subsubsection{Dissolution Study}

The dissolution profile of repaglinide and its adducts was obtained using USP XII apparatus (paddle type tribune). The medium consisted of $900 \mathrm{~mL}$ of buffer solution (phosphate buffer $\mathrm{pH}$ 7.4). The stirring speed was set at $60 \mathrm{rpm}$. The media was already filtered, degassed and maintained at $37 \pm 0.5{ }^{\circ} \mathrm{C}$. The samples equivalent to $10 \mathrm{mg}$ of repaglinide were used. The samples of $5 \mathrm{ml}$ were withdrawn after 15, 30, 60, 90, 120 and $240 \mathrm{~min}$ and analyzed till the absorbance of the solution attains a constant value. 


\section{Results and Discussion}

\subsection{Preparation of Pharmaceutical Adducts by Slow Evaporation Technique}

The adducts were prepared by slow evaporation technique containing drug to coformer ratio of $1: 2 \mathrm{w} / \mathrm{w}$ respectively for all batches i.e. B1, B2, B3, B4, B5, B6, B7, B8 (Table 2). However, the crystals of adducts were obtained only in B1 and B2 and no crystals were in batches B3- B8 as can be seen in Table 2. The formation of any other form of product such as dispersions is ruled out as the both the components i.e. drug and coformers are taken in molar ratios.

Table 2: Product obtained in all the batches.

\begin{tabular}{|l|l|l|}
\hline S. No. & Batch & Adduct formation \\
\hline 1 & B1 & Yes \\
\hline 2 & B2 & Yes \\
\hline 3 & B3 & No \\
\hline 4 & B4 & No \\
\hline 5 & B5 & No \\
\hline 6 & B6 & No \\
\hline 7 & B7 & No \\
\hline 8 & B8 & No \\
\hline
\end{tabular}

\subsection{Characterization of Adducts}

\subsubsection{Percentage Yield}

The percentage yield of obtained adducts is given in Table 3. It can be seen that there is high percentage yield of the product by slow evaporation method of preparation.

The percentage yield for both the batches i.e. B1 and B2 was found to be $>90 \%$ with the higher yield for B1 i.e. $95.36 \pm 0.12 \%$, which shows the greater ability of respective co-former (Soluplus) to prepare pharmaceutical adducts. There was no co-crystal formation for batch B3 to B8 which may be due to acidic nature of drug showing no bonding with acid group of coformers.

Table 3: Percentage yield of obtained adducts.

\begin{tabular}{|l|l|l|}
\hline S. No. & Batch & \% yield \\
\hline 1 & B1 & $95.36 \pm 0.12$ \\
\hline 2 & B2 & $96.36 \pm 0.15$ \\
\hline 3 & B3 & 0 \\
\hline 4 & B4 & 0 \\
\hline
\end{tabular}

\begin{tabular}{|l|l|l|}
\hline 5 & B5 & 0 \\
\hline 6 & B6 & 0 \\
\hline 7 & B7 & 0 \\
\hline 8 & B8 & 0 \\
\hline
\end{tabular}

\subsubsection{Melting Point}

The difference in range of capillary melting of repaglinide adducts suggested formation of new solid phases (Table 4). Further studies have been performed to confirm the existence of a new phase.

Table 4: Melting points of repaglinide and its adducts.

\begin{tabular}{|l|l|}
\hline Ingredient & Melting point $\left({ }^{\circ} \mathbf{C}\right)$ \\
\hline Repaglinide & 126.8 \\
\hline Soluplus & 70 \\
\hline B1 & 160 \\
\hline HPMC & 220 \\
\hline B2 & 231 \\
\hline
\end{tabular}

\subsubsection{Drug Entrapment}

The drug entrapment for both the batches was found to be $>88 \%$ with maximum entrapment of $96.03 \pm 1.23 \%$ for B1 (Soluplus) showing the ability of co-former to combine with required amount of drug (Table 5).

Table 5: Drug entrapment in repaglinde adducts.

\begin{tabular}{|l|l|l|}
\hline S. No. & Batch & Drug entrapped \pm SD \\
\hline 1 & B1 & $94.19 \pm 0.95$ \\
\hline 2 & B2 & $92.98 \pm 0.74$ \\
\hline
\end{tabular}

\subsubsection{Fourier Transform Infra-Red Spectroscopy}

Thespectra of of adducts formed and repaglinide showed certain differences in the peak positions which are shown in figures 2, 3 and 4. The most prominent peaks are at wavenumber $3305 \mathrm{~cm}^{-1}$ and $1685 \mathrm{~cm}^{-1}$ for $-\mathrm{NH}$ stretch and $-\mathrm{C}=\mathrm{O}$ stretch respectively (Table 6). The variations in these two peaks is clearly evident in both the adducts as shown in Table $7 \& 8$. The range of wavelength in which this peak appears corresponds to the literature values for an alkyl stretch (C-H stretch) and C-O stretch respectively. It is evident that there is formation of bond between carboxylic moiety of repaglinide and hydrogen bond forming atom present in the coformers e.g. $-\mathrm{OH}$ of ascorbic acid, gallic acid and benzoic acid; $-\mathrm{N}$ of caffeine and thiourea; $-\mathrm{CO}$ of HPMC and soluplus. This suggests formation of new surfaces due to hydrogen bonding. 


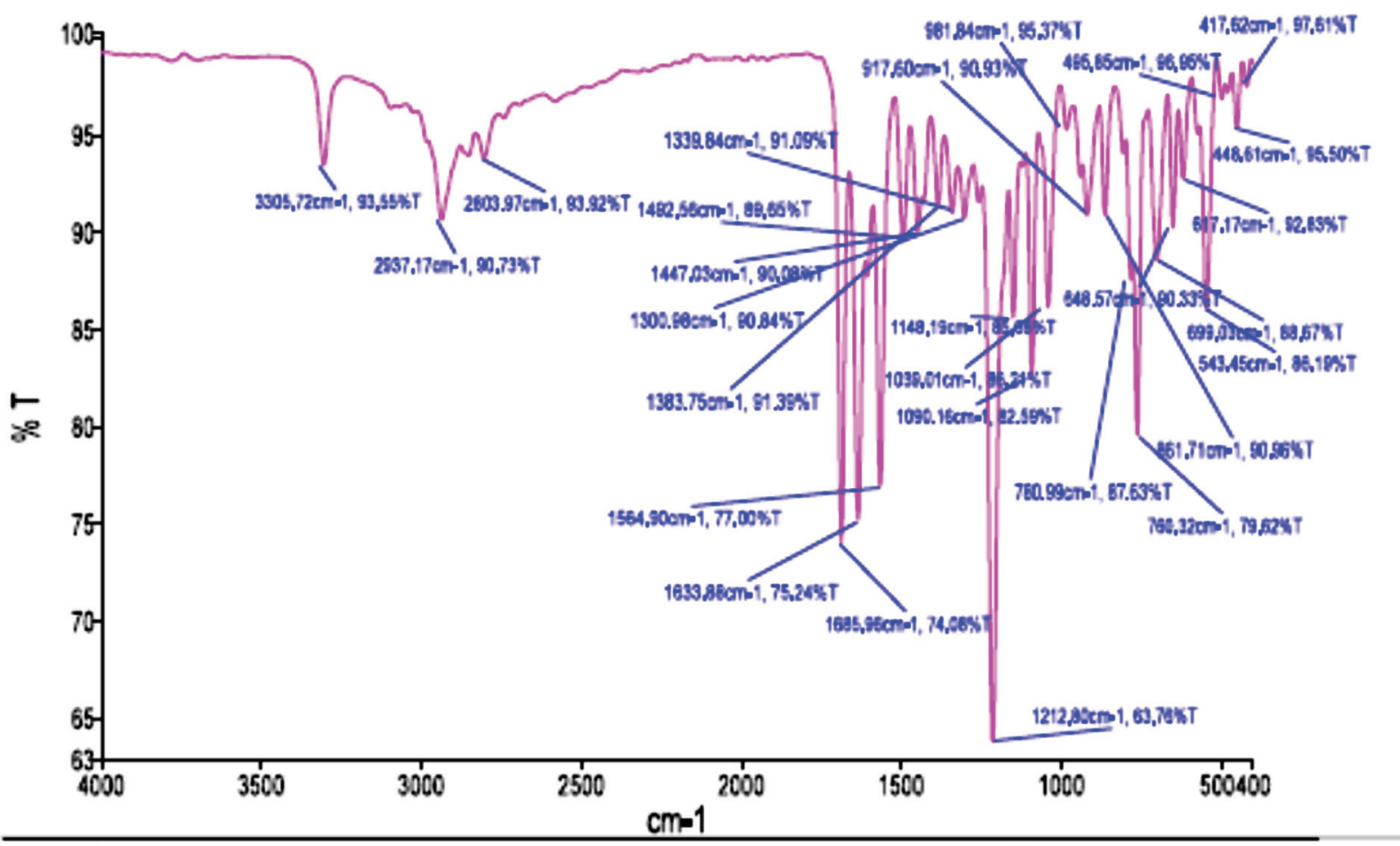

Figure 2: FTIR spectrum of repaglinide.

Table 6: FTIR data of repaglinide.

\begin{tabular}{|l|l|l|l|}
\hline S. No. & Interpretation & IR range & Observed peak $\left.\mathbf{c m}^{-1}\right)$ \\
\hline 1 & N-H stretch & $3200-3400$ & 3305.72 \\
\hline 2 & C-H stretch & $2850-3000$ & 2937.17 \\
\hline 3 & C=O stretch & $1680-1710$ & 1685.96 \\
\hline 4 & C-O stretching & $1180-1260$ & 1212.80 \\
\hline
\end{tabular}

Table 7: FTIR data of repaglinide-soluplus adduct.

\begin{tabular}{|l|l|l|l|}
\hline S. No. & Interpretation & IR range & Observed peak $\left.\mathbf{( c m}^{-1}\right)$ \\
\hline 1 & N-H stretch & $3200-3400$ & 3416.96 \\
\hline 2 & C-H stretch & $2850-3000$ & - \\
\hline 3 & C=O stretch & $1680-1710$ & 16.8 \\
\hline 4 & C-O stretch & $1180-1260$ & - \\
\hline
\end{tabular}

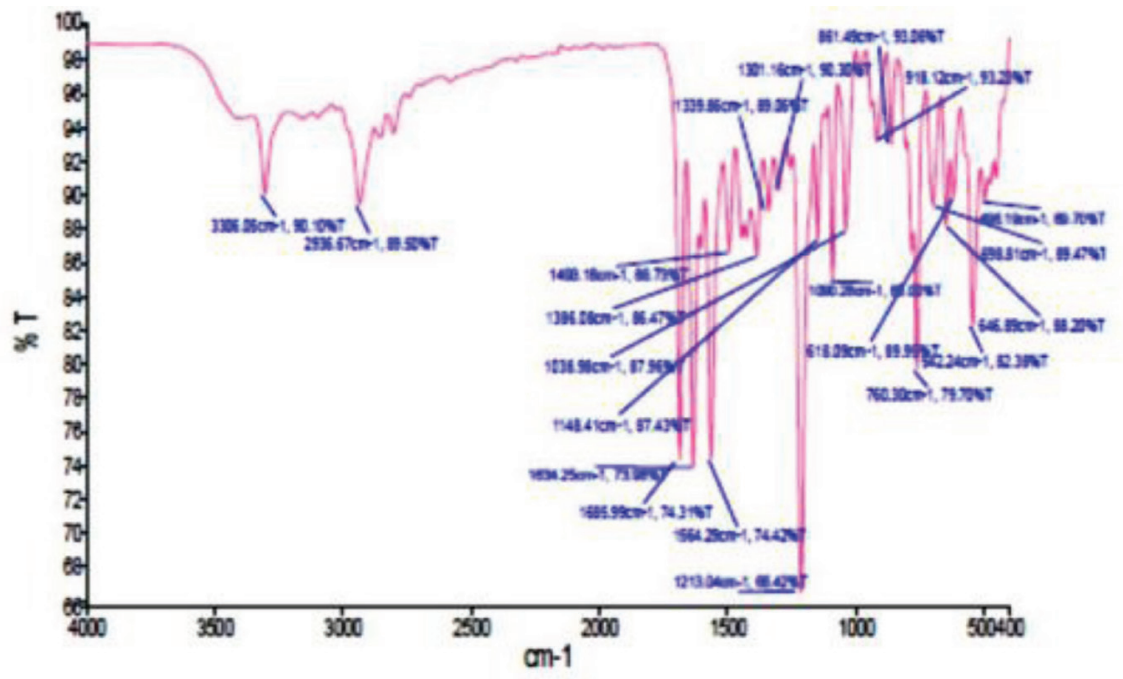

Figure 3: FTIR spectra of repaglinide-soluplus adducts. 


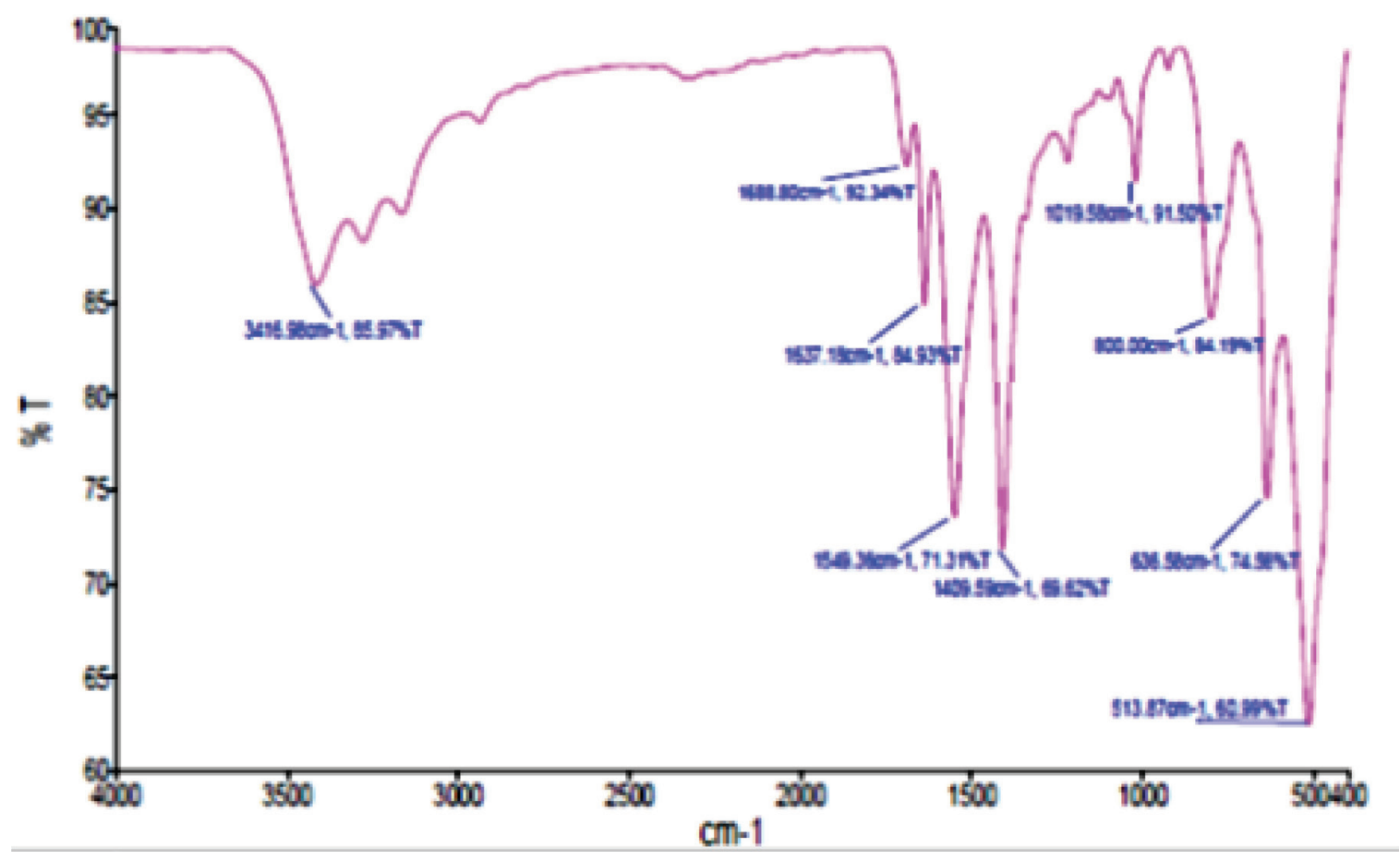

Figure 4: FTIR spectra of repaglinide-HPMC adducts.

Table 8: FTIR data of repaglinide-HPMC adduct.

\begin{tabular}{|l|l|l|l|}
\hline S. No. & Interpretation & $\begin{array}{l}\text { IR range } \\
\mathbf{c m}^{-1}\end{array}$ & Observed peak $\left.\mathbf{( c m}^{-1}\right)$ \\
\hline 1 & N-H stretch & $3200-3400$ & 3414.96 \\
\hline 2 & C-H stretch & $2850-3000$ & - \\
\hline 3 & C $=$ O stretch & $1680-1710$ & 1637.8 \\
\hline 4 & C-O stretch & $1180-1260$ & - \\
\hline
\end{tabular}

\subsubsection{DSC Analysis}

The DSC spectrum of repaglinide and its adducts is shown in Figure 5. It can be that the melting of repaglinde is observed at $126.8{ }^{\circ} \mathrm{C}$. The DSC graph of adducts showed that the peak area and height decreased suggesting drug has interacted with the conformer resulting in the formation of a new phase which has different melting point from repaglinide.

\subsubsection{Optical Microscopy}

The optical microscopic images suggest the formation of crystalline structures in B2. The batch B2 shows the formation of needle shaped co-crystals while B1 (Soluplus) shows an amorphous type of structure suggesting greater solubility and ability of co-former to form co-crystals (Figure 6).

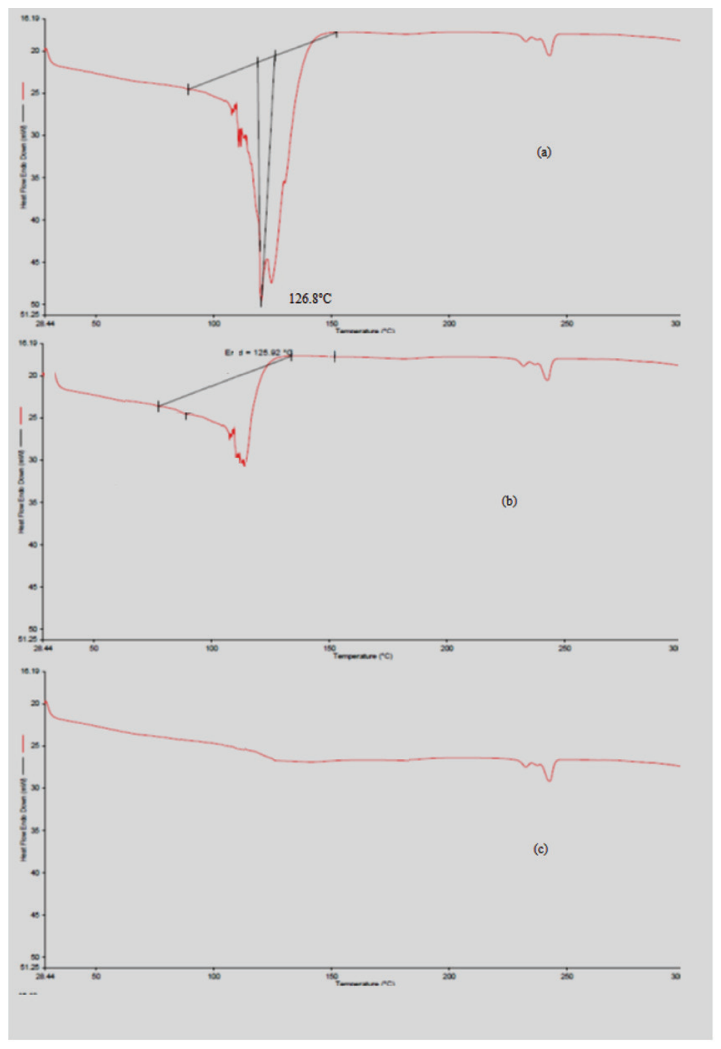

Figure 5: DSC thermogram of (a) Repaglinide (b) Rep-soluplus (c) Rep-HPMC. 


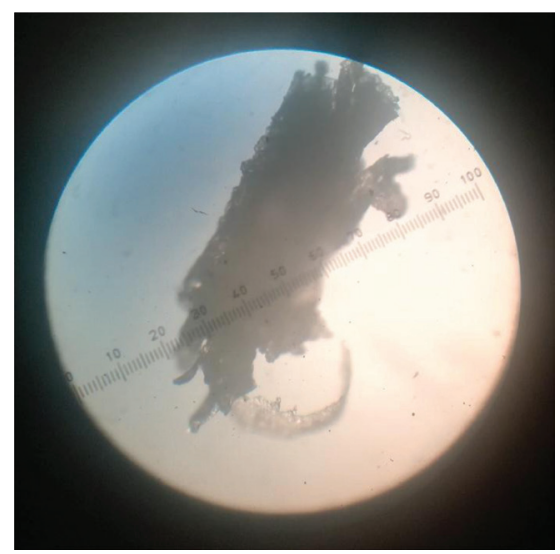

B1

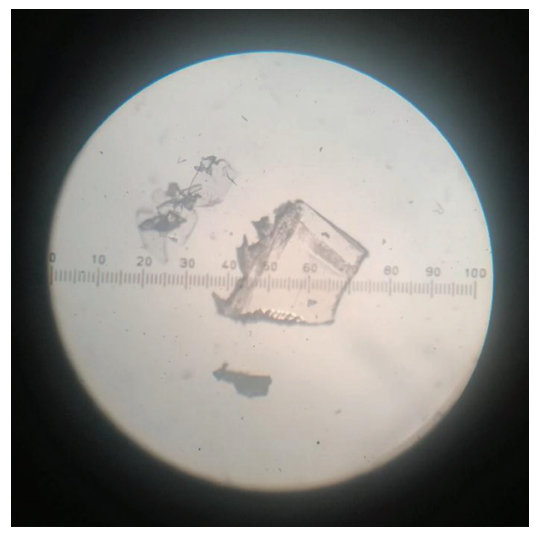

B2

Figure 6: Optical microscopic images of various batches of adducts.

\subsubsection{Aqueous Solubility}

The solubility was found to increase in repaglinide in each batch. But, the batch B1 (Soluplus) shows greater increase in aqueous solubility of repaglinide showing the greater ability of this co-formers to increase the aqueous solubility of poorly water soluble drugs (Table 9).

Table 9: Aqueous solubility of repaglinide and its adducts.

\begin{tabular}{|l|l|l|}
\hline S. No. & Batch & Solubility \pm SD (\%) \\
\hline 1 & Rep & $30.12 \pm \mathbf{0 . 3 8}$ \\
\hline 2 & B1 & $80.88 \pm 0.53$ \\
\hline 3 & B2 & $38.34 \pm 1.25$ \\
\hline
\end{tabular}

\subsubsection{Dissolution Study}

The dissolution graph of repaglinide and the molecular adducts is shown in Figure 7. The dissolution profile suggests an increase of 1.1 and 2.25 times in the dissolution rate for molecular adducts with soluplus and HPMC respectively.

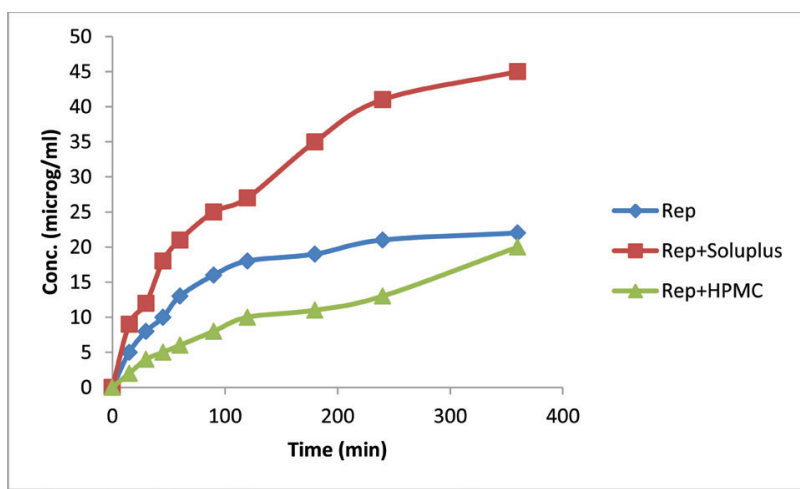

Figure 7: Dissolution profile of repaglinide and its adducts.

\section{Conclusion}

From the above study it can be concluded that poor solubility of pharmaceutical agents is a major limitation which can be overcome by preparing molecular adducts without affecting the chemical composition of the API. The pharmaceutical adducts formed in the present study showed better solubility and dissolution profile as compared to the pure repaglinide.

\section{Acknowledgements}

The authors acknowledge the Oniosome Healthcare Pvt. Ltd. for carrying out the analysis of the samples.

\section{Authorship Contribution}

The work has been carried out by Ms. Sharen Gill under the guidance of Dr Poonam Arora.

\section{Funding}

No funding has been availed from any institution to carry out this work.

\section{Conflict of Interest}

The authors report no conflict of interest.

\section{References}

Babu, N.J. \& Nangia, A. (2011). Solubility advantage of amorphous drugs and pharmaceutical cocrystals. Crystal Growth \& Design, 11(7), 2662-2679. https://doi.org/10.1021/cg200492w

Bhogala, B.R., Basavoju, S. \& Nangia, A. (2005). Threecomponent carboxylic acid- bipyridine lattice inclusion host. Supramolecular synthesis of ternary 
cocrystals. Crystal growth \& design, 5(5), 1683-1686. https://doi.org/10.1021/cg058012p

Desiraju, G.R. (2010). Crystal engineering: a brief overview. Journal of Chemical Sciences, 122(5), 667-675. https://doi.org/10.1007/s12039-010-0055-2

Friščić, T. \& Jones, W. (2010). Benefits of cocrystallisation in pharmaceutical materials science: an update. Journal of Pharmacy and Pharmacology, 62(11), 1547-1559. https://doi.org/10.1111/j.2042-7158.2010.01133.x

Mirza, S., Miroshnyk, I., Heinämäki, J. \& Yliruusi, J. (2008). Co-crystals: an emerging approach for enhancing properties of pharmaceutical solids. Dosis : farmaseuttinen aikakauskirja, 24(2), 90-96.

Sekhon, B.S. (2009). Pharmaceutical co-crystals - a review. ARS Pharmaceutica, 50(3), 99-117.
Shan, N., \& Zaworotko, M.J. (2008). The role of cocrystals in pharmaceutical science. Drug Discovery Today, 13(9-10), 440-446.

https://doi.org/10.1016/j.drudis.2008.03.004

Upadhyay, N., Shukla, T.P., Mathur, A., \& Manmohan, J.S. (2011). Pharmaceutical co-crystal: an emerging approach to improve physical property. International Journal of Pharmaceutical Science Review \& Research, 8(1), 144-148.

Yadav, A.V., Shete, A.S., Dabke, A.P., Kulkarni, P.V., \& Sakhare, S.S. (2009). Co-crystals: a novel approach to modify physicochemical properties of active pharmaceutical ingredients. Indian Journal of Pharmaceutical Sciences, 71(4), 359-370. https://doi.org/10.4103/0250-474X.57283
旬

CHITKARA

\section{Journal of Pharmaceutical Technology, Research and Management}

Chitkara University, Saraswati Kendra, SCO 160-161, Sector 9-C, Chandigarh, 160009, India

Volume 8, Issue 1

May 2020

ISSN 2321-2217

Copyright: [C2020 Sharen Gill and Poonam Arora] This is an Open Access article published in Journal of Pharmaceutical Technology, Research and Management (J. Pharm. Tech. Res. Management) by Chitkara University Publications. It is published with a Creative Commons Attribution- CC-BY 4.0 International License. This license permits unrestricted use, distribution, and reproduction in any medium, provided the original author and source are credited. 